\title{
Closely related Symbiodinium spp. differ in relative dominance in coral reef host communities across environmental, latitudinal and biogeographic gradients
}

\author{
T. C. LaJeunesse ${ }^{1,2,6, *}$, R. Bhagooli ${ }^{3}$, M. Hidaka ${ }^{3}$, L. deVantier $^{4}$, T. Done ${ }^{4}$, \\ G. W. Schmidt ${ }^{1}$, W. K. Fitt ${ }^{2}$, O. Hoegh-Guldberg ${ }^{5}$ \\ ${ }^{1}$ Department of Plant Biology, Plant Sciences Building, ${ }^{2}$ Institute of Ecology, University of Georgia, Athens, Georgia 30602, USA \\ ${ }^{3}$ Department of Chemistry, Biology and Marine Sciences, University of the Ryukyus, Nishihara, Okinawa 903-0213, Japan \\ ${ }^{4}$ Australian Institute of Marine Science, Private Mail Box 3, Townsville, Queensland 4810, Australia \\ ${ }^{5}$ Centre for Marine Studies, University of Queensland, St. Lucia, Queensland 4072, Australia \\ ${ }^{6}$ Present address: Department of Biology, Florida International University, University Park Campus, OE 24511200 \\ SW 8th Street, Miami, Florida 33199, USA
}

\begin{abstract}
The diversity and community structures of symbiotic dinoflagellates are described from reef invertebrates in southern and central provinces of the Great Barrier Reef (GBR), Australia, and Zamami Island, Okinawa, Japan. The symbiont assemblages from region to region were dominated by Clade C Symbiodinium spp. and consisted of numerous host-specific and/or rare types (specialists), and several types common to many hosts (generalists). Prevalence in the host community among certain host-generalist symbionts differed between inshore and offshore environments, across latitudinal (central versus southern GBR) gradients, and over wide geographic ranges (GBR versus Okinawa). One particular symbiont (C3h) from the GBR had a dramatic shift in dominance. Its prevalence ranged from being extremely rare, or absent on high-latitude reefs to dominating the scleractinian diversity on a mid-latitude inshore reef. These changes occurred among coral fauna whose larvae must acquire symbionts from environmental sources (horizontal symbiont acquisition). Such differences did not occur among 'vertical transmitters' such as Porites spp., Montipora spp. and pocilloporids (corals that directly transmit symbionts to their offspring) or among those hosts displaying 'horizontal acquisition', but that associate with specific symbionts. Most host-specialized types were found to be characteristic of a particular geographic region (i.e. Okinawa versus Central GBR versus Southern GBR). The mode of symbiont acquisition may play an important role in how symbiont composition may shift in west Pacific host communities in response to climate change. There is no indication that recent episodes of mass bleaching have provoked changes in hostsymbiont combinations from the central GBR.
\end{abstract}

KEY WORDS: Symbiodinium • Zooxanthellae biodiversity · Coral symbiosis · Phylogeography • Community structure

Resale or republication not permitted without written consent of the publisher

\section{INTRODUCTION}

The development and employment of molecular genetic tools has initiated a new era in ecological, evolutionary and systematic discovery. This is especially true for microscopic and morphologically cryptic orga- nisms such as dinoflagellate endosymbionts (zooxanthellae) that promote the survival and growth of stony corals, soft corals, and related species that construct and/or thrive on tropical reefs (Rowan \& Powers 1991, Rowan et al. 1997, LaJeunesse 2001, 2002, Baker 2003). Ribosomal gene sequence comparisons indicate that 
coral endosymbionts, in the genus Symbiodinium, are highly diverse and evolutionarily old (Trench 1997, Rowan 1998). This revelation is not especially remarkable given the diverse environments, biological complexity and ages of the ecosystems where these symbioses are dominant. Nevertheless, our growing understanding of this diversity and its ecological significance has direct implications to addressing issues regarding the impact of global climate change on nature conservation (Hoegh-Guldberg 1999).

Improved awareness of symbiont diversity, physiology and host-specificity contributes to hypotheses on how corals respond to climate change (Buddemeier \& Fautin 1993, Baker 2001). Differences in partner combinations across latitudinal, longitudinal and environmental (e.g. irradiance) gradients have been reported for a number of host taxa (Baker \& Rowan 1997, Rowan et al. 1997, LaJeunesse \& Trench 2000, RodriquezLanetty et al. 2001, Van Oppen et al. 2001, Burnett 2002). Such patterns could be related to symbionts with different sensitivities to thermal stress (IglesiasPrieto et al. 1992, Iglesias-Prieto \& Trench 1997, Jones et al. 1998, Warner et al. 1999), irradiance (Chang et al. 1983, Iglesias-Prieto et al. 2004), and/or host-specificity (Colley \& Trench 1983, LaJeunesse 2001). These findings underlie the hypothesis that partner-switching creates new partnerships that are better adapted to changes in physical-environmental conditions (Rowan \& Powers 1991, Buddemeier \& Fautin 1993, Baker 2001). Can the formation of new partnerships (i.e. 'switching') take place rapidly over ecological time scales or is this capacity limited by slower evolutionary processes that may not keep pace with the current rate of environmental change (HoeghGuldberg et al. 2002)?

Further description of the variability between hosts and their symbionts over environmental, latitudinal and geographic ranges should help define the spatial and temporal limitations governing the extent to which these systems may respond and possibly adjust to future climate change. To this end, large-scale surveys of Symbiodinium spp. diversity and ecology have been initiated on stony corals and related host groups from the southern Great Barrier Reef (GBR), Hawaii, and Caribbean regions (Loh et al. 1998, Baker 1999, LaJeunesse 2002, LaJeunesse et al. 2003, 2004).

The genus Symbiodinium is partitioned systematically into a number of major phylogenetic divisions or clades. To date, most Pacific reef cnidarians are found to harbor Symbiodinium spp. from Clade C, whereas host assemblages in the Caribbean associate commonly with Symbiodinium spp. from Clades A and (especially) B (Baker \& Rowan 1997, LaJeunesse et al. 2003). The shared ecological dominance in the Caribbean of Clade B with Clade C Symbiodinium spp. resulted possibly from environmental change in this region during the Pliocene-Pleistocene transition (Jackson 1994, Collins et al. 1996, Budd 2000, Baker 2003, LaJeunesse et al. 2003). Harsher (e.g. colder) physical-environmental conditions in the region during this time may have promoted the partial ecological displacement of Clade C by Clade B (Baker 2003, LaJeunesse et al. 2003).

Each Symbiodinium clade comprises a yet undetermined number of closely related 'types' or species that cluster at the end of long diverging branches (Rowan 1998, LaJeunesse 2002, Baker 2003). Molecular genetic identification of ecologically different Symbiodinium spp. within each major clade has been achieved by comparing internal transcribed spacer region (ITS 1 and 2) sequences of ribosomal RNA genes (Baillie et al. 2000, LaJeunesse 2001, 2002, Van Oppen et al. 2001. These genetically distinct types possess unique environmental (depth zonation), ecological (host range) and geographic distributions. Some types have wide geographic distributions (Baillie et al. 2000, LaJeunesse 2001 ) and are found in numerous host taxa (LaJeunesse 2002). Most others display limited geographic ranges and/or associate specifically with a particular host genus or species. Because the host is a major axis of resource (habitat) utilization, each type is defined as being a 'generalist' or 'specialist' depending on their relative capacity to associate with different host taxa (LaJeunesse et al. 2003).

The world's largest contiguous reef system, the Great Barrier Reef (GBR), off the east coast of Australia, offers an appropriate setting to explore host-symbiont dynamics because communities from different latitudes (a total range of nearly $15^{\circ}$ ), physical environments (warm turbid inshore versus colder clear offshore waters), and those with different bleaching histories (including frequency and severity) can be examined. Systematic surveys were first begun in the most southern region of the GBR, Heron Island of the Capricorn bunker group (LaJeunesse et al. 2003), after initial studies by Loh et al. (1998). The majority of host taxa from the southern GBR associate with one of several generalist symbionts from the Clade $\mathrm{C}$ lineage. While these types were the most ecologically common, the greatest proportion of Symbiodinium spp. diversity consisted of host-specific and/or rare types, specialists, also from Clade C (LaJeunesse et al. 2003). The log normal distribution of symbiont abundance and/or prevalence (few highly prevalent generalists and many rare specialists) is consistent with reefs surveyed from the Caribbean (LaJeunesse 2002).

Among other remaining questions, it is not known if the patterns described above hold for GBR reefs systems closer to the equator, where many of the midshelf and inshore reefs suffered greater bleaching and 
mortality than those in the southern GBR (Berkelmans \& Oliver 1999, Skirving \& Guinotte 2001). Moreover, there may be an inherent latitude-related pattern in host-symbiont partnerships across coral communities, similar to that already documented for several host taxa (LaJeunesse \& Trench 2000, Loh et al. 2001, RodriquezLanetty et al. 2001). Finally, we sought to determine if the relatively low host-to-symbiont diversity in the southern GBR is consistent with lower-latitude GBR reefs. The coral diversity in the southern province of the GBR is substantially lower than in more northern areas, forming a high-latitude subset of the total GBR host-species pool (Veron 1995, 2000).

We also conducted surveys at Zamami Island, part of the Kerama Islands, located 20 to $40 \mathrm{~km}$ west of Okinawa, in the northern hemisphere, for purposes of comparing GBR Symbiodinium spp. diversity with that on a reef from another region in the western Pacific. Unlike Okinawa to the immediate east, Zamami Island was not severely impacted by bleaching and represents a more 'pristine' reef analogous to Heron Island at the same relative latitude in the opposite hemisphere.

\section{MATERIALS AND METHODS}

In May 2003, symbiotic invertebrates were collected by SCUBA on reefs from the central Great Barrier Reef. Collections were conducted in late March 2002 at Zamami Island, of the Kerama Islands, approximately $30 \mathrm{~km}$ west of the south end of Okinawa Island, Japan.

As with previous studies attempting to quantify the general diversity of symbionts from a reef system (LaJeunesse 2002, LaJeunesse et al. 2003, 2004), an emphasis was placed on sampling from a diverse range of hosts (over 75 genera, 154 species) consisting of hard corals, soft corals, gorgonians, anemones, zoanthids, corallimorphs, tridacnid clams and nudibranchs. Importantly, members of a host taxon found in a particular reef environment and geographic region usually possess the same symbiont type (Baker 1999, LaJeunesse 2002), with some exceptions (cf. Loh et al. 2001) (i.e. 80 to $100 \%$ of individuals of Coral C sampled at Depth D on Reef R will have Symbiont S). Differences in host diversity between various reef habitats and locations made sampling from a proportional number of species difficult. For example, half of the host genera collected at Rib and Feather Reefs were sampled at the Curaçao Island fringing reef. The low generic host diversity at this inshore location and limited field time made collections at this reef unproportional to those of the mid-shelf reefs.

Collections from shallow (1 to $4 \mathrm{~m}$ ) and deeper (>10 m) reef zones were made to obtain corals living under different irradiances. Host taxa distributed at both depths were collected to identify possible 'polymorphisms'. Sampling colonies from deep and shallow habitats increased the probability of identifying coral species that associate with more than 1 symbiont (Baker 1999). This work did not attempt to quantify the complete diversity of symbionts with which a particular host associates, but rather represents a 'snapshot' of the symbionts across a wide array of hosts in a particular community. A study of complete diversity would require exhaustive sampling of the host from every environment in which it is found.

Before sampling, each host individual was photographed (overall morphology and close-up) using a Nikon Cool-Pix 5000 digital camera in an underwater housing (Subal, Netherlands) for later identification. The images obtained were compared with taxonomic references and identification guides (e.g. Veron 2000, Fabricius \& Alderslade 2001), and most hosts were identified to the genus and species level.

Fragments representative of the host colony or individual were collected and processed to separate symbionts from host tissues, as previously described (LaJeunesse et al. 2003). The resulting algal pellet was preserved in 20\% DMSO, $0.25 \mathrm{M}$ EDTA in NaClsaturated water (Seutin et al. 1991). Algal pellets from Zamami Island were preserved in CHAOS solution (4M guanidine thiocyanate, $0.5 \%$ sarkosyl, $2.5 \mathrm{mM}$ Tris-HCL ( $\mathrm{pH}$ 8.0) and 0.1 M $\beta$-mercaptoethanol).

The Wizard DNA preparation protocol by Promega, modified by LaJeunesse et al. (2003), was used to extract nucleic acids. Approximately $30 \mathrm{mg}$ of material was placed into $1.5 \mathrm{ml}$ microcentrifuge tubes with $250 \mu \mathrm{g} 0.5 \mathrm{~mm}$ glass beads and $600 \mu \mathrm{l}$ nuclei lysis buffer (Promega) and bead-beaten for 2 min at $800 \times g$ in a Biospec Mini-Beadbeater. The lysate was then incubated with $0.1 \mathrm{mg} \mathrm{ml}^{-1}$ Proteinase $\mathrm{K}$ for 1 to $2 \mathrm{~h}$ at $65^{\circ} \mathrm{C}$, followed by incubation with $6 \mu \mathrm{g} \mathrm{m} \mathrm{m}^{-1}$ RNase at $37^{\circ} \mathrm{C}$ for $10 \mathrm{~min}$. Protein precipitation buffer $(250 \mu \mathrm{l})$ was then added and the extract incubated on ice for 10 to $15 \mathrm{~min}$. After centrifugation for $5 \mathrm{~min}$ at $24000 \times g$, $600 \mu \mathrm{l}$ of supernatant was transferred to a second $1.5 \mathrm{ml}$ tube containing $700 \mu \mathrm{l}$ isopropanol $100 \%$ and $50 \mu \mathrm{l} \mathrm{NaAc}$ (3 M, pH 5.6). Following incubation on ice for $10 \mathrm{~min}$, the precipitated DNA was centrifuged and the pellet washed with $70 \%$ EtOH. The DNA was centrifuged again for $5 \mathrm{~min}$, dried, and resuspended in $70 \mu \mathrm{H}_{2} \mathrm{O}$ and $4 \mu \mathrm{l} 10 \times$ Tris-EDTA.

While numerous molecular markers are now employed for the study of Symbiodinium diversity (Baker 2003), the internal transcribed spacer region (ITS) method appears to provide adequate resolution between ecologically distinctive forms while being sufficiently conserved to enable assessment of different types to be compared among communities from distant geographic areas. For each DNA extract, the ITS 2 region 
was amplified using primers 'ITS 2 clamp' and 'ITSintfor 2' (LaJeunesse \& Trench 2000) with the touch-down thermal cycle given in LaJeunesse (2002). Products from these PCR reactions were electrophoresed for $9.5 \mathrm{~h}$ on denaturing gradient gels ( 45 to $80 \%$ ) using a CBScientific system. Gels stained with Sybergreen (Molecular Probes) for 30 min were photographed using a Kodak digital imaging system or with standard black-and-white 677 polaroid film.

The PCR-DGGE fingerprint signatures from each sample were compared with profiles from earlier data sets (LaJeunesse et al. 2003, 2004). The identification of new symbiont types was verified by excising brightly stained bands from the denaturing gel. The DNA was eluted in $500 \mu \mathrm{l} \mathrm{HOH}$ for several days, re-amplified using the same primer set without the guaninecytosine-rich clamp extension in a standard PCR thermal cycle profile (annealing of $52^{\circ} \mathrm{C}$ for 40 cycles), and sequenced as previously described (LaJeunesse 2002).

To demonstrate the reproducibility of the PCR reaction by this method, 2 samples that showed a similar profile involving 2 co-dominant ITS variants, but with different relative band intensities, were repeatedly amplified and compared. This verified whether clear differences in band intensity were the product of PCR artifact or reflected true differences in copy number between variant sequences within a genome.

Maximum parsimony under the default settings of PAUP* 4.0b10 (Swofford 1999) was employed for inferring a phylogeny. Sequences were edited and aligned manually using Sequence Navigator Version 1.0 software (ABI, Division of Perkin Elmer). Clade C possesses ITS 2 sequence types distinguished by a low number of base substitutions and/or insertion/deletions. With maximum parsimony (MP), informative sequence gaps as a 5th character state were included, delayed-transformation (DELTRAN) was chosen for character state optimization, and no model of molecular evolution was assumed. Sister lineages to Clade C represented by Fr1 (sensu Pochon et al. 2001) and F1 in Clade F (Symbiodinium kawagutii; LaJeunesse 2001) were used as outgroups (GenBank Sequences AJ291520 and AF333515). Phylogenetic analyses, neighbor-joining (NJ) and Bayesian inference of phylogeny were also performed and the resulting tree topologies compared to MP. Baysian analyses were implemented using the software MrBayes Version 3.0b4 (Huelsenbeck \& Ronquiest 2001). We ran 500000 generations under the HKY85 models of sequence evolution, beginning with an unspecified tree topology, and no defined prior probabilities. The log probability reached stationarity between 50000 and 75000 generations. This burn-in was not discarded and therefore the posterior probabilities presented below are conservative estimates. A bootstrap resampling was also conducted for 500 replicates to assess relative branch support. Given that there are a small number of critical base substitutions (out of 321 aligned characters, 230 were invariable and 32 were parsimony-informative), bootstrapping probably underestimates the actual support for sub-clade radiations. A second bootstrapping was performed with the resampling value doubled (642 characters). An unrooted phylogenetic analysis of Clade $\mathrm{C}$ sequences was also performed and topology was compared with the rooted one.

Finally, symbiont community similarity from each region was assessed statistically using the Sørensen coefficient. It is preferred here to the Jaccard method because it weights species, or types that are common between regions over types found in only 1 area.

\section{RESULTS}

\section{Symbiodinium spp. diversity}

We identified 32 symbiont 'types' from biopsies of 74 different host genera sampled at the 3 reefs surveyed from the central GBR (Table 1) and 20 types from 31 host genera from Zamami island (Table 2). PCR-DGGE fingerprint profiles representing 'new' types from the Central GBR and Okinawa are shown in Fig. 1a,b respectively. All belong to Clade $\mathrm{C}$, the group most prevalent among host taxa surveyed at all 3 regional locations (Tables $1 \& 2$ ). New Clade $C$ types characterized were C1j (AY589732), C1k (AY589733), C31a (AY589746), C31b (AY589767), C40 (AY258485), C40a (AY589747), C40b (AY589748), C55 (AY589759), C56 (AY589760), C57 (AY589761), C58 (AY589762), C59 (AY589763), C60 (AY589764), C61 (AY589765), C62 (AY589766), C64 (AY589768), C65/65a (AY589769/ AY589770), C67 (AY686647), C68 (AY589772), C69/ C69a (AY589773/AY686648), C70 (AY589774), and C71/C71a (AY589775/AY589776). A nexus alignment of all Clade C ITS types from the west Pacific is available upon request from the corresponding author.

Due to the dominance of Clade C Symbiodinium spp., the diversity and prevalence of symbionts from other clades was low. Types A3 and A6 (AY686646) were identified from tridacnid clam tissues from the central GBR and Okinawa respectively. Clade B members were absent from our collections, except Type B1 in the soft coral genus Nephthia from the southern GBR (LaJeunesse et al. 2003).

Only 3 ITS types in Clade D were identified (Fig. 2). Type D1a was found sporadically among faviids, mussids and oculinids from the central GBR, and agaricids and fungiids from Zamami Island in typically shallow habitats (1 to $4 \mathrm{~m}$ ). Its fingerprint is known from hosts from the western Indian Ocean, central Pacific 

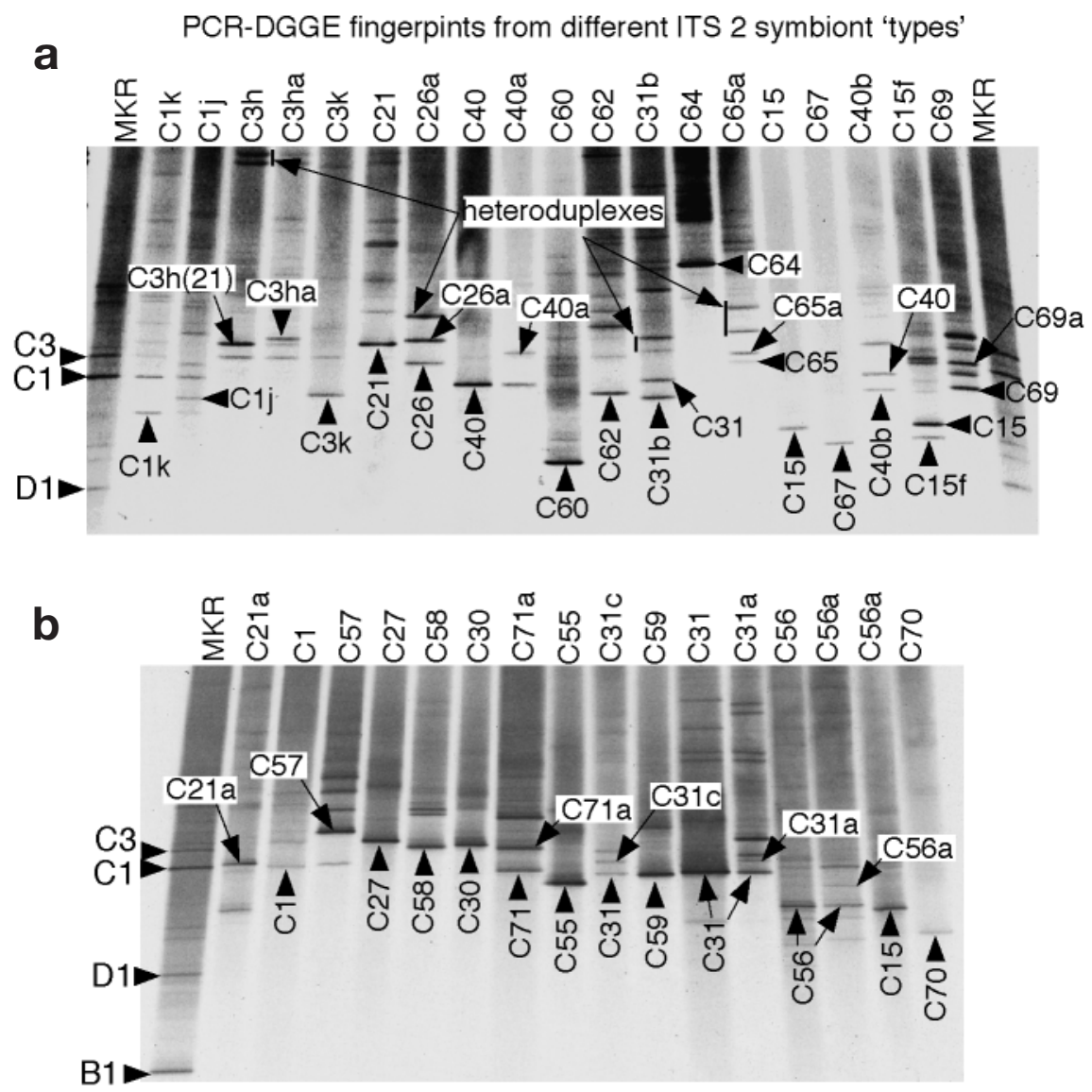

Fig. 1. Symbiodinium spp. (a) Representative PCR-DGGE ITS 2 fingerprints (profiles) of Lineage $C$ types observed in hosts from the Central Great Barrier Reef. Identities, given as alphanumeric designations, and diagnostic band(s) to which each refers are compiled for those species newly reported: uppercase letters indicate lineage or clade, numbers represent ITS type, and lowercase letters denote a rDNA paralog, when one is present within the genome and diagnostic of the entire fingerprint. (b) PCR-DGGE ITS 2 fingerprints of endosymbionts from Zamami Island, Okinawa Japan. Profiles from common symbionts C3, C1, and D1 were pooled and run in the marker (MKR) lane. Examples of heteroduplexes are indicated; they are artifacts of the DGGE-PCR process present in fingerprints of genomes with more than 1 dominant ITS 2 sequence

Ocean, and Caribbean Sea (LaJeunesse 2002, LaJeunesse et al. 2005, A. Baker \& T. LaJeunesse unpubl.). Type D2 (AY686649) was found only among some Acropora spp., indicating that it may be specialized to this particular genus. Type D3 (AY686650) was found at only 1 location and in 1 host taxon (Clavularia sp. collected at $6 \mathrm{~m}$ ). The rarity and probable host-specific nature of this type indicates that Clade D also consists of geographically widespread host-generalists and more localized, host-specific and/or rare forms.

\section{PCR-DGGE analysis of Type C3h}

The ITS 2 PCR-DGGE fingerprint profiles of Type C3h from 19 host genera are illustrated in Fig. 3a. C3h was never identified in acroporids, however. The genome of this particular Symbiodinium sp. contains 2 codominant ITS 2 sequences across the ribosomal repeat array. Essentially it is intermediate between Types C3 and $\mathrm{C} 21$, a genome either caught in the process of concerted evolution from the ancestral sequence of $\mathrm{C} 3$ to the more derived sequence of $\mathrm{C} 21$, or the result of sexual recombination between Types C3 and C21. The designation $\mathrm{C} 3 \mathrm{~h}$ was therefore given to this fingerprint profile to distinguish it from Types C3 and C21. The upper $\mathrm{C} 21 / \mathrm{C} 3 \mathrm{~h}$ band is consistently brighter than the lower and suggests that the relative copy number between each

Fig. 2. Symbiodinium spp. PCRDGGE ITS 2 fingerprints of Clade D identified from the western Pacific. D1a was found sporadically among faviid, mussid and oculinid genera, usually related to shallow environments but not completely dependent on depth. This fingerprint is found in hosts from the western Indian Ocean, central Pacific and Caribbean (LaJeunesse 2002, A. Baker \& T. LaJeunesse unpubl.). Type D2 was found only in Acropora spp. from the central GBR and may represent a hostspecialized symbiont. Type D3 was found at Curaçao Island in octocoral Clavularia sp., but questions about its prevalence and host-specificity remain sequence is fixed in the genome of this organism. There was one exception; the C3 band from Goniastrea pectinata (Feather Reef, $15 \mathrm{~m}$ ) was brighter than the C21/C3h band and the faint banding pattern found higher up in that lane differed from the other profiles.

To test whether this difference was a random artifact of the amplification process, 8 PCR replicate reactions were conducted on the DNA extract from Goniastrea pectinata that gave rise to this variant and on a representative that produced the normal profile. There was no discernible fingerprint variation from reaction to reaction and the profiles from each example remained consistent with original analyses (Fig. 3b). The C3h profile from $G$. pectinata is therefore different from the other $\mathrm{C} 3 \mathrm{~h}$ profiles. Because these similar fingerprint 


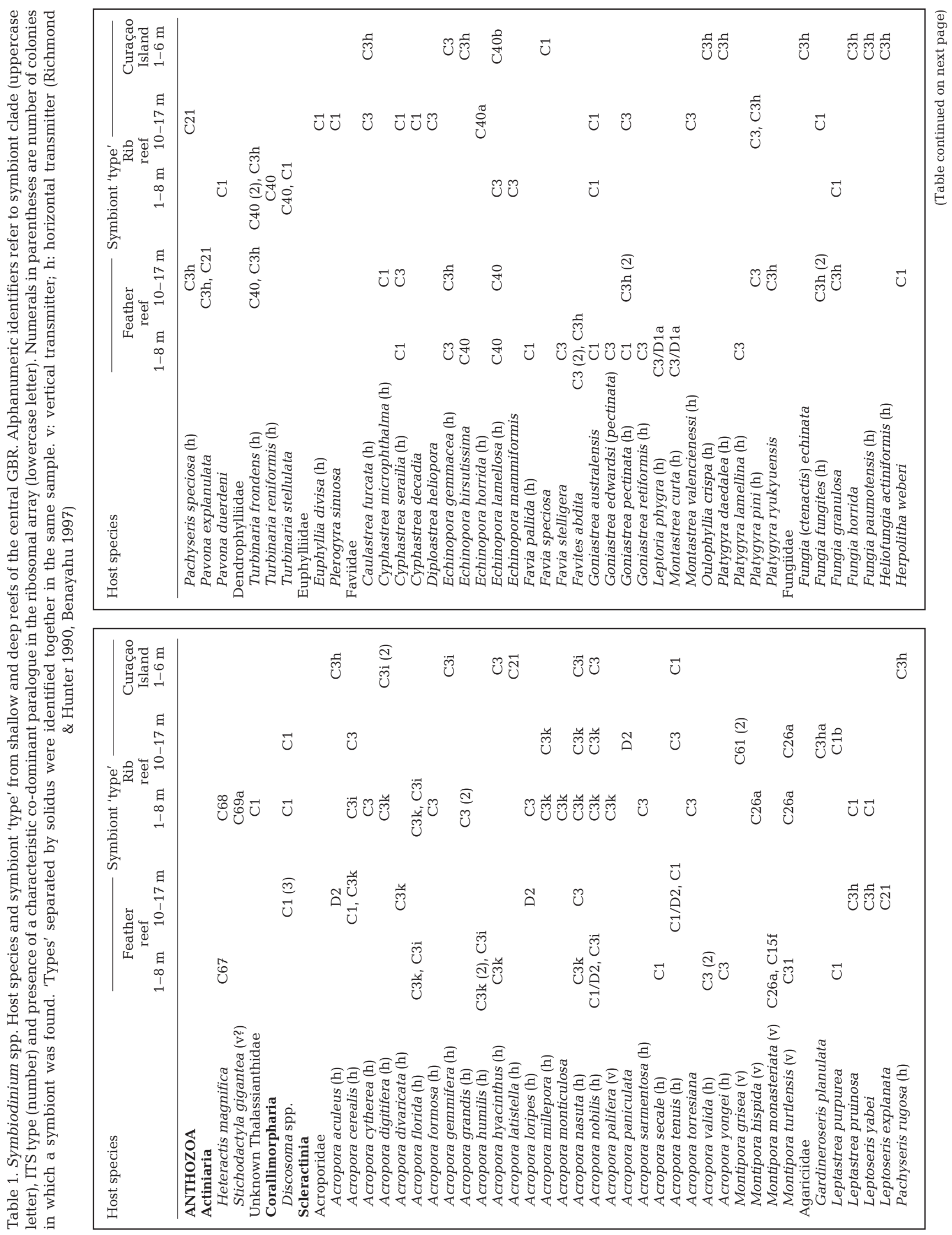




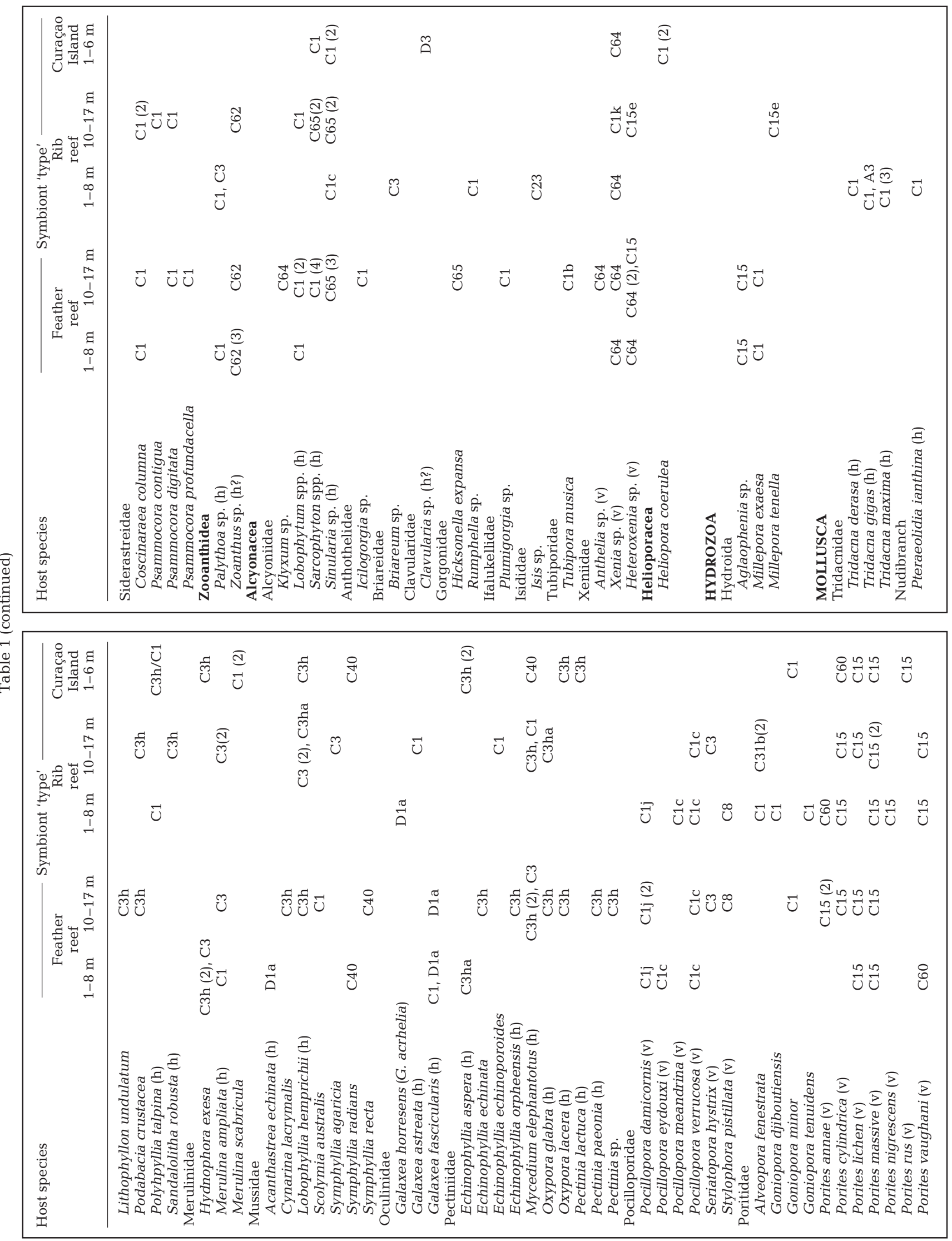


Table 2. Symbiodinium spp. Host species and symbiont 'type collected' at 1 to $10 \mathrm{~m}$ depth on reefs off Zamami Island, Okinawa, Japan. Further details as in Table 1

\begin{tabular}{|c|c|c|c|}
\hline Host taxon & Symbiont 'type' & Host taxon & Symbiont 'type' \\
\hline ANTHOZOA & & Fungiidae & \\
\hline Actiniaria & & Fungia danai (h) & $\mathrm{C} 27$ \\
\hline Unkown anemone & $\mathrm{C} 70$ & Fungia scutaria (h) & C1 (2) \\
\hline Scleractinia & & Fungia spp. (h) & $\mathrm{C} 27, \mathrm{C} 1$ \\
\hline Acroporidae & & Sandalolitha robusta $(\mathrm{h})$ & $\mathrm{C} 1 / \mathrm{D} 1 \mathrm{a}$ \\
\hline Acropora abrolhosensis & $\mathrm{C} 1$ & Merulinidae & \\
\hline Acropora aspera & C3 (2) & Hydnophora exesa & C21a (2), C27 \\
\hline Acropora cerealis & C3 (2) & Hydnophora rigida & $\mathrm{C} 21 \mathrm{a}(2), \mathrm{C} 1$ \\
\hline Acropora copiosa & $\mathrm{C} 3$ & Mussidae & \\
\hline Acropora digitifera $(\mathrm{h})$ & C3 (2) & Lobophyllia robusta & $\mathrm{C} 21 \mathrm{a}$ \\
\hline Acropora divaricata & $\mathrm{C} 3, \mathrm{C} 1(2)$ & Symphyllia sp. (h) & C21a \\
\hline Acropora donei & C3 (3), C1 & Symphyllia radians & C21a (3) \\
\hline Acropora exquisita & C3 & Oculinidae & \\
\hline Acropora florida $(\mathrm{h})$ & $\mathrm{C} 3$ & Galaxea fascicularis (h) & $\mathrm{C} 21 \mathrm{a}$ \\
\hline Acropora listeri & $\mathrm{C} 3$ & Pectiniidae & \\
\hline Acropora microphthalma (h) & $\mathrm{C} 3$ & Echonophyllia sp. & $\mathrm{C} 21 \mathrm{a}$ \\
\hline Acropora nobilis $(\mathrm{h})$ & $\mathrm{C} 1, \mathrm{C} 3$ & Pectinia alcicornis & $\mathrm{C} 21 \mathrm{a}$ \\
\hline Acropora palifera & $\mathrm{C} 1(2)$ & Pectinia sp. & $\mathrm{C} 21 \mathrm{a}$ \\
\hline Acropora secale & C3 (2) & Pocilloporidae & \\
\hline Acropora selago & C3 (2) & Pocillopora damicornis (v) & C1c (2) \\
\hline Acropora subglabra & C3 & Pocillopora eydouxi (v) & C1c (3) \\
\hline Acropora tenuis (h) & C3 (2) & Seriatopora hystrix (v) & $\mathrm{C} 59$ \\
\hline Acropora valida (h)) & C3, C3i & Stylophora pistillata (v) & $\mathrm{C} 1(4)$ \\
\hline Acropora verweyi & C1 & Poritidae & \\
\hline Astreopora myriophthalma & C1 (3) & Alveopora sp. & $\mathrm{C} 27(2)$ \\
\hline Montipora danae (v) & C31 & Porites cylindrica (v) & C56a (2) \\
\hline Montipora efflorescens (v) & C30 & Porites lichen $(\mathrm{v})$ & C56 (2) \\
\hline Montipora mollis (v) & C58 (2) & Porites lutea $(\mathrm{v})$ & C15 (3) \\
\hline Montipora venosa (v) & C31a, C31 & Porites massive (v) & C15 (3) \\
\hline Montipora verrucosa (v) & $\mathrm{C} 31$ & Porites sp. (v) & C56 (2) \\
\hline Montipora spp. (v) & C31, C31a, C31c, C1 (2) & Porites rus (v) & $\mathrm{C} 15$ \\
\hline Agariciidae & & Porites silimaniana (v) & C15 \\
\hline Pachyseris rugosa & C1 (3) & Siderastreidae & \\
\hline Pachyseris speciosa & $\mathrm{C} 27$ & Coscinaraea sp. & C1 (3) \\
\hline Pavona varians & D1a & Coscinaraea exesa & $\mathrm{C} 1 / \mathrm{C} 27$ \\
\hline Astrocoeniidae & $C 1$ & Zooanthidea & \\
\hline $\begin{array}{l}\text { Palauastrea ramosa } \\
\text { Faviidae }\end{array}$ & C1 (3) & Zoanthus sp. (h) & C1 (2) \\
\hline Caulastrea chalcidicum & $\mathrm{C} 1$ & Alcyonacea & \\
\hline Cyphastrea japonica & C1 & Alcyoniidae & \\
\hline Cyphastrea sp. & C21a (2) & Sarcophyton sp. (h) & C71a \\
\hline Echinopora lamellosa (h) & $\mathrm{C} 1, \mathrm{C} 3$ & HYDROZOA & \\
\hline Echinopora pacificus & $\begin{array}{r}\mathrm{C} 3 \\
\mathrm{C} 3\end{array}$ & $\begin{array}{l}\text { HYDRUZUA } \\
\text { Millepora sp. }\end{array}$ & C57 (6) \\
\hline Favia stelligera & $\mathrm{C} 3$ & MOLLUSCA & \\
\hline Favites halicora & $\mathrm{C} 21 \mathrm{a}$ & Tridacnidae & \\
\hline Platygrya sp. (h) & C55 & Tridacna sp. (h) & A6 \\
\hline
\end{tabular}

profiles lack additional bands that could be sequenced to distinguish them on phylogenetic grounds, they were both conservatively scored as the same type. Genetic structure occurs at all levels of a lineage down to the individual (Avise 2000). It is not surprising that the recent use of more variable markers indicates that these ITS lineages may be further subdivided (Santos et al. 2004).

\section{Clade C phylogeny}

The genetic relatedness of western Pacific Clade C Symbiodinium spp. is presented in Fig. 4. Internal topology remained consistent under $\mathrm{MP}, \mathrm{NJ}$ or Baysian inference of phylogeny methods, both rooted and unrooted. The exact point at which the outgroup branch joins Clade $\mathrm{C}$ varied slightly, dependent on whether Fr1 (Clade $\mathrm{H}_{\text {; }}$ Pochon et al. 2005) and/or F1 (Clade F; LaJeunesse 2001) were used separately or together. The effect of long-branch attraction may sometimes supplant the outgroup connection with the most ancestral sequence of this clade. However, a combination of ecological (host-generalist), biogeographic (pandemic distribution), and phylogenetic (ancestral sequence to a radiation of numerous hostspecific and/or rare types) evidence suggest Types C3 or C1 are probably the most ancestral. The posi- 


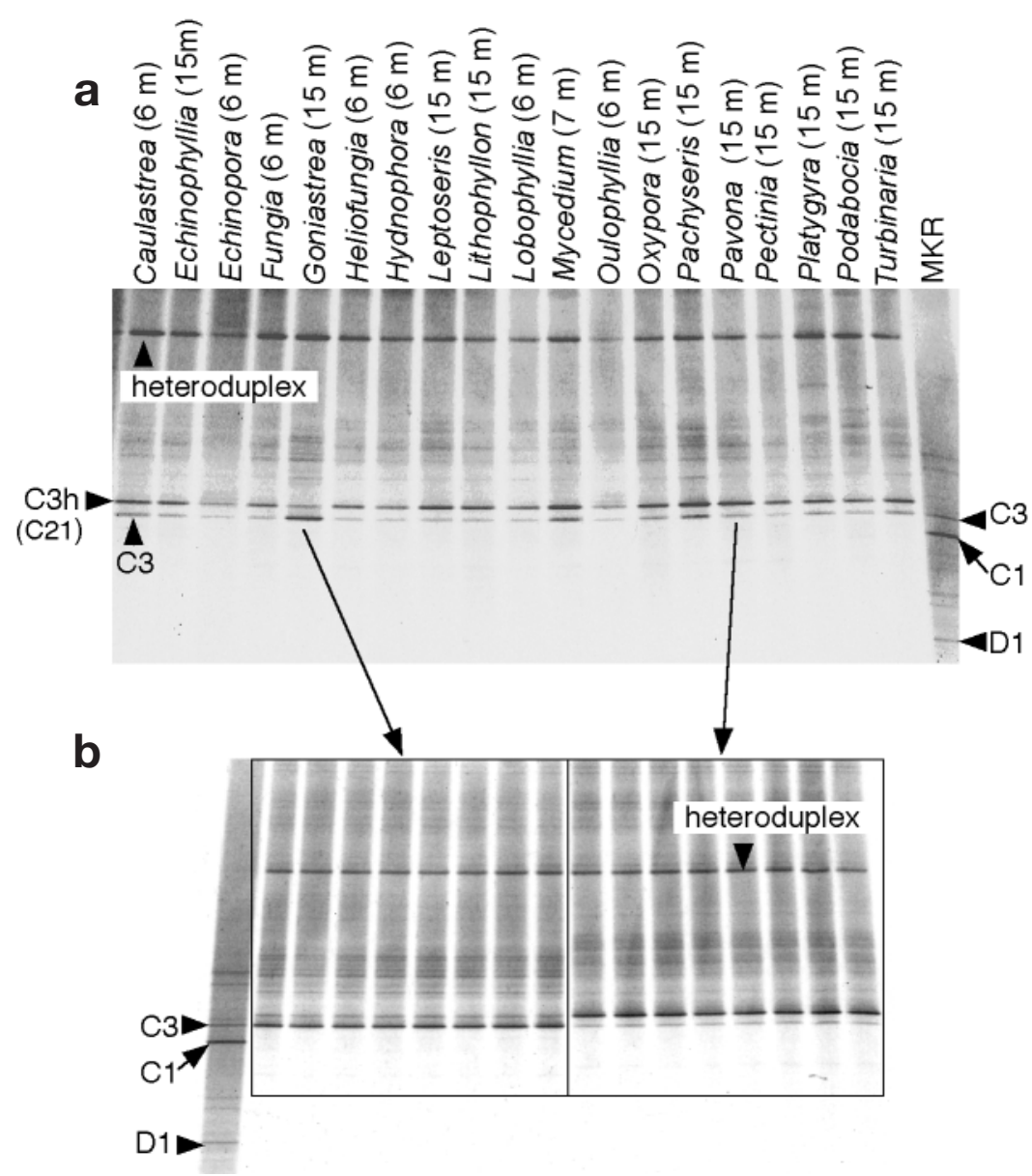

Fig. 3. Symbiodinium spp. (a) PCR-DGGE ITS2 fingerprints of Type C3h, collected from 19 different scleractinian genera from deep or low-light reefs on the central GBR. Rare in the southern GBR, it achieved its highest prevalence in the host community surveyed from the turbid inshore location at Curaçao Island, central GBR. Relative intensities of each band are similar from sample to sample and indicate that these sequences are intragenomic variants. It is postulated that ribosomal array contains 2 codominant ITS 2 sequences (C3 and C21) and represents an intermediate condition of concerted evolution from C3 to C21. Alternatively, it could represent a recombinant of these 2 distinctive species. (b) Repeatability of the PCR-DGGE method. The sample that gave rise to a distinctive 'variant' whose C3 band was brighter (hence greater copy number) than the C3h/C21 band was amplified again along with a representative exhibiting a 'normal' profile. No discernible variation was detected from reaction to reaction, and fingerprint profiles remained consistent with original analyses. Therefore, C3h profile from Goniastrea pectinata can be viewed as qualitatively different from the others but, because of limits in discerning these 2 profiles through sequencing, they are both conservatively scored as the same type

tion of Type C61 was unstable and certain branch connections within the C21 sub-clade varied slightly. Several well-developed sub-cladal lineages containing multiple types (viz. C15 and C21 and their offshoots) correspond with host genera that transfer their symbionts directly from generation to generation (Fig. 4b). Some host-specialized and/or rare symbionts, especially those identified from species of Porites, Montipora and Pocillopora, were found at all locations, but many others exhibited slight sequence differences that distinguished them regionally (Fig. 4b).

\section{Similarity of symbiont communities and differences in relative dominance}

Type C1 dominated most host communities. Several other types were found at each location, but the majority of diversity consisted of less common, geographically restricted, rare and/or host-specific types. Reefs from distant geographic regions exhibited marked differences in their symbiont communities (Fig. 5). The Sørensen percentage of dissimilarity estimates between Zamami Island and Heron Island, Zamami Island and the central GBR, and the central GBR and Heron Island were 68, 68, and $60 \%$ respectively. The 3 reefs surveyed from the central GBR region shared essentially the same community composition of symbiont types (dissimilarity estimates calculated between Rib and Feather Reefs were $21 \%$; Fig. 5). This valuation of community difference is probably an overestimate because of the presence or absence of undersampled rare types and limited, uneven, host taxa sampling at each reef. Because only half of the host genera collected a Rib and Feather Reefs were sampled at Curaçao Island, statistical comparisons of their community compositions were not made. Clearly, the symbiont community at Curaçao is a subset of that found on offshore reefs.

Differences among the relative dominance of some common symbiont types were observed from reef to reef (Fig. 5). C3h differed in its relative abundance between the midshelf reefs of Rib and Feather and the inshore reef at Curaçao Island (within $150 \mathrm{~km}$ of each other). It was the most common type at the relatively turbid, inshore site at Curaçao, where it occurred in more than $50 \%$ of host genera surveyed. Often found in certain scleractinian hosts sampled below $15 \mathrm{~m}$ on mid-shelf reefs (Fig. 3a), it occured in more genera on Feather Reef (approx. 30\%) than on Rib Reef (approx. 8\%). In contrast, C3h was rare at the southern GBR location of Heron Island, being found in 1 sample from Pavona maldivensis.

As was the case for the outer GBR reefs, C1 was the most prevalent symbiont at the Zamami Island loca- 


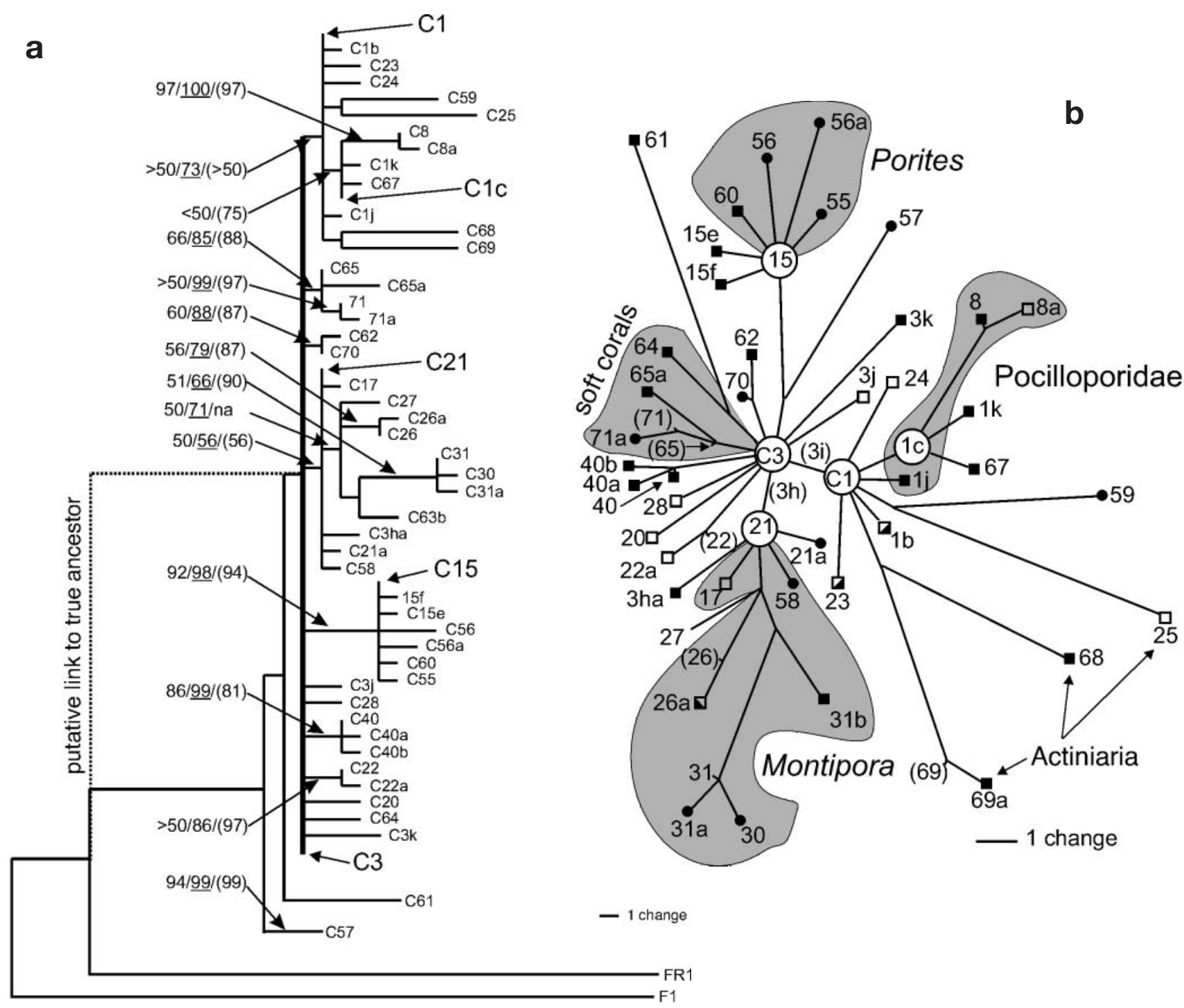

Fig. 4. Symbiodinium spp. Phylogenetic reconstruction of western Pacific Clade C based on ITS 2 and partial 5.8S sequences. Maximum parsimony phylograms are both (a) rooted and (b) un-rooted; both have very similar topologies. (a) The point of connection between Clade C and outgroup lineages differed depending on whether Fr1 or F1 were used separately or together. Dotted line indicates putative connection to Type C3 (bold vertical line) and is based on phylogeographic and ecological evidence for being ancestral among Clade $\mathrm{C}$ types. Values indicated for each internal branch node are bootstrap estimates (first number), bootstrap with resampling doubled to compensate for high proportion of invariant characters (underlined), and Bayesian posterior probabilities (in parentheses); internal nodes that lack posterior probabilities are based on insertion/deletions not assessed by Bayesian methods. (b) Radiations of host-specific and/or rare types from a small number of widely distributed and/or host-generalist types are shown in this unrooted topology. Localization among types to specific geographic regions is indicated by symbols on branch termini: () southern GBR; (घ) central GBR; $(\mathbf{Z})$ both GBR regions; $\bullet$ Zamami Island, Okinawa. Encircled types were found at all locations

tion. But here, Types C21a and C27 were also among the most common. The complex PCR-DGGE fingerprint observed for Type C21a is thus far unique to the Okinawa, NW Pacific, region. C27 was previously found to occur in Pavona spp. from Hawaii (LaJeunesse et al. 2004) and in 1 Pavona sp. specimen from Heron Island (LaJeunesse et al. 2003).

\section{DISCUSSION}

Variability in symbiont dominance is influenced by life history of the host

External physical conditions may influence specificity in symbioses that begin anew after each genera- 


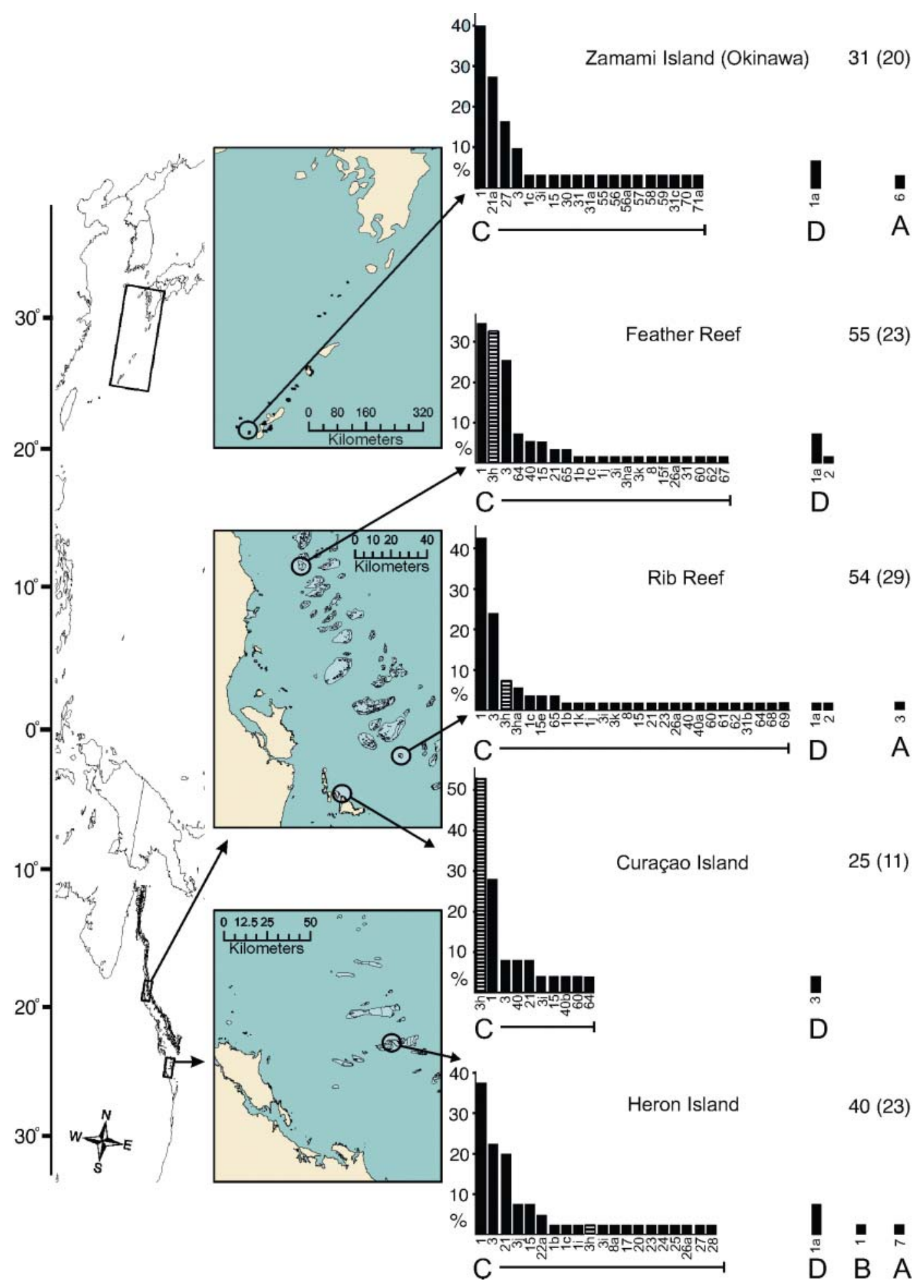

Fig. 5. Symbiodinium spp. Comparison of diversity and community structures across latitudinal, environmental, and geographic gradients. Percentage of host genera surveyed is presented on $y$-axes and the different symbiont types in order of prevalence among host genera along the $x$-axes. Each community comprises a few types common to many host taxa and numerous hostspecific and/or rare species that characterize each region surveyed. Type $\mathrm{C} 1$ is usually most common in each community. Excluding Type C3, each region contains secondary generalists that are prevalent only in their respective regions (e.g. Types C21a and C27 in Zamami Island, C3h on the central GBR, and C21 from the southern GBR). Striped bars show relative prevalence of Type C3h at different locations over the GBR. Number of host genera surveyed at each site is given on upper-right of each graph, with total numbers of symbiont types (displaying different ITS 2 PCR-DGGE fingerprints) in parentheses 
tion. A majority of western Pacific corals broadcastspawn eggs and sperm that do not contain symbionts (Richmond \& Hunter 1990). Therefore, coral populations from this expansive region may be highly susceptible to shifts in symbiont type from generation to generation. We found that environment and latitude affected the relative dominance of certain Symbiodinium spp. within hosts that acquire their symbionts from environmental sources (Fig. 5, Tables 1 \& 2). Because adult colonies often show long-term stability with a particular symbiont type (Coffroth et al. 2001, Goulet \& Coffroth 2003, Iglesias-Prieto et al. 2004, LaJeunesse et al. 2005), the present host-symbiont community structure among broadcast-spawning coral taxa probably reflects the environmental conditions under which these symbioses were initially established. Over several generations, change in environment could cause significant shifts in the type of symbiont dominating the host community; however, this scenario assumes that the extent and rate of change does not exceed the physiological capability of each potential partner. Because there is the likelihood of significant climatic disturbances in these communities over the coming decades (Hoegh-Guldberg 1999, Kleypas et al. 1999), continued monitoring will document the range of partner flexibility (Baker 2003) and determine if symbiont change can ultimately sustain these reef corals.

Symbiont C1 was dominant on most reefs, but a number of generalist taxa exhibited great regional variability in their relative dominance. Temperature and light fluctuations associated with decreasing latitude may explain differences between the central GBR and southern GBR symbionts (Fig. 5). Within the central GBR region, higher temperatures and perhaps greater turbidity at the inshore site of Curaçao Island may be key selective factors that explain the offshoreto-inshore gradient of $\mathrm{C} 3 \mathrm{~h}$ dominance. Also, little is known about the environmental abundances of Symbiodinium spp. If $\mathrm{C} 3 \mathrm{~h}$ is particularly abundant in the planktonic or benthic assemblages nearer to shore, this may in part explain differences in its host community dominance (Baker \& Rowan 1997).

Specialized and/or rare symbionts that displayed limited ranges in geographic and host distribution accounted for major differences in symbiont composition from region to region. Many of these symbionts associate with hosts that pass on symbionts directly to their offspring. For example, montiporid corals broadcast eggs containing symbionts (Richmond \& Hunter 1990). They predictably associate with one of a number of closely related types that are a part of the montiporid sub-clade radiating from C21 (Fig. 4b). The majority of members from this sub-clade associate exclusively with Montipora spp. They have particular geographic distributions, and are common in 1 region but rare or absent in other places. Type C26a occurred rarely in Montipora spp. from the southern GBR, but was common among these corals from the central GBR. It was absent from Zamami Island, yet was identified from M. capitata in Hawaii living at depths below $20 \mathrm{~m}$ (LaJeunesse et al. 2004) and, therefore, appears to have a large geographic range. Another type, C31, was common among montiporids from Zamami Island but rare on the central GBR. It associates with the common brown color morph of $M$. capitata (at depths above $15 \mathrm{~m}$ ) from Hawaii (LaJeunesse et al. 2004). These widely distributed host-specialists contrast with other montiporid symbionts surveyed from the NW Pacific, SW Pacific, and Hawaii that appear to have more limited ranges. These distributions, involving widely dispersed specialized types versus regionally endemic types, are also observed for poritid and pocilloporids corals, and among non-scleractinian groups such as the alcyonarians.

\section{Implications of mass coral bleaching}

Many of the central GBR reefs experienced mass coral bleaching in 1998, 2002 and 2004, with most severe effects occurring on inshore reefs (Berkelmans \& Oliver 1999, Marshall \& Baird 2000). Such episodes of stress and reduction in symbiont population density may facilitate a shift in the symbiont type that becomes dominant upon recovery, either through uptake from the environment (Buddemeier \& Fautin 1993, Baker 2001) or proliferation of surviving cells remaining within the polyps (Baker 2001). For example, symbiont shifts in the population of ecologically dominant Pocillopora verrucosa were reported in the eastern Pacific following the 1997 El Niño-related bleaching event (Glynn et al. 2001). It cannot be determined if the increase of Clade D (specifically Type D1) in proportion to Clade $\mathrm{C}$ (possibly involving different types within this clade) among individual coral colonies was due to natural selection of thermally resistant combinations or whether symbiont population shifts occurred via proliferation of a minor population of Clade $\mathrm{D}$ within colonies as they recovered (Baker 2001).

Symbiodinium spp. from Clade D are often found to associate with hosts from thermally variable and turbid environments and colonies or individuals recovering from bleaching episodes (Baker 2001, Toller et al. 2001, Van Oppen et al. 2001, Chen et al. 2003, IglasiasPrieto et al. 2004). Various Clade D members are consequently viewed as thermally tolerant, stress-resistant, opportunistic Symbiodinium spp. In the present study, Curaçao Island was also surveyed to determine if the inshore environment favored types from 
Clade D over those from Clade C. Contrary to our expectation that Clade D would dominate the host community on the warmer inshore reefs (cf. Van Oppen et al. 2001), its prevalence was not different from that on reefs further offshore. Questions remain as to what extent Clade D Symbiodinium spp. may allow coral populations to compensate under continued sea-surface warming (Baker 2001, Little et al. 2004). Comparative physiological analyses will need to be employed to learn what attributes or limitations account for the changes in the host community dominance of these Symbiodinium spp. These geographic and environmentally relatable shifts are ultimately of interest in describing evolutionary processes between host and symbiont lineages through time (Thompson 1994).

Heron Island and Zamami Island, both high-latitude reefs, have had limited exposures and experiences with bleaching. While their symbiont community structures are similar, the difference in composition of Clade C Symbiodinium spp. is clearly a product of their geographic separation. Thus for the present, the severity or frequency of mass coral bleaching in the central GBR does not seem to have resulted in a shift in symbiont population structures that cannot be otherwise explained by geographic, latitudinal and normal environmental factors. These differences in Symbiodinium spp. distribution probably took many generations to become established.

\section{Symbiont diversity relative to host diversity}

Many Pacific hosts associate with closely related Symbiodinium spp. in Clade C (Baker \& Rowan 1997, Loh et al. 1998, Baker 1999, LaJeunesse et al. 2003, 2004). Initially, host assemblages from southern GBR reefs were reported to have lower relative symbiont diversity of ITS types than reefs from the Caribbean (LaJeunesse et al. 2003). Subsequent work in Hawaii has also observed this inverse relationship between host and symbiont diversity (LaJeunesse et al. 2004). The enumeration of ITS types found on the central GBR was low in relative proportion to the number of host genera surveyed. This trend offers further support of an inverse relationship between host and symbiont diversity. Genetic divergence and symbiont speciation through host-specialization is common for hosts in which symbionts are directly transferred from generation to generation (Futuyma \& Moreno 1988, Douglas 1998) a process that is exemplified by poritid, pocilloporid and montiporid corals and their symbionts. The greater composition of hosts in the Caribbean $(63 \%$ brood out of the 19 coral species investigated) and Hawaii (29\% out of the 12 investigated) whose symbionts are vertically transferred in comparison to the west Pacific (GBR
$6 \%$ out of 144 , Okinawa $4 \%$ out of the 26 coral species investigated; Richmond \& Hunter 1990), explains some of these inverse relations, but not all.

Symbiont-specificity and the presence of host-specific symbionts were found for hosts that rely upon horizontal symbiont transmission. Among others, species of Acropora (with Types C3i, C3k and D2) (some Acropora [Isopora] brood their larvae) and Zoanthus (with Type C62) (Ryland 1997), possessed Symbiodinium spp. not identified in other host taxa (cf. Van Oppen 2004). Regions with a high diversity of hosts involved in acquiring symbionts from the environment may favor the maintenance of highly prevalent generalist symbionts (Law 1985). Host rarity would present problems for passively dispersed symbionts and newly settled aposymbiotic larvae in finding each other within a diverse host community over effectively vast spatial scales.

\section{Emergent patterns of Symbiodinium spp. biogeography}

Phylogeography, relating patterns of geographic distribution with genetic relatedness, is a powerful tool in assessing historical and evolutionary processes (Avise 2000). Our current understanding of Symbiodinium diversity and geographic distribution remains limited, but as more ITS data are gathered, patterns of dispersal and geographic isolation/connectivity are beginning to emerge. Widely distributed symbiont types tend to be host-generalists and are, phylogenetically, ancestral to symbionts that are more specialized. Based on ecological, biogeographic, and phylogenetic grounds, we interpret Types C1 and C3 as the ancestral stock from which numerous host-specific, regionally endemic and/or rare types have radiated. Divergent, host-specific and/or rare forms tend to have narrow geographic ranges and are probably endemic. These patterns of geographic partitioning are reinforced by genetic surveys at the 'population level' that have identified clear geographic structure within specific ITS lineages (Santos et al. 2003, 2004).

Certain symbionts show exceptions to these basic patterns of geographic partitioning. Their host specificity and biogeography leads to hypotheses concerning the evolutionary processes that occur between host and symbiont lineages. Type C27 is widely distributed throughout the Pacific but has different host relations in different regions. It is rare in the southern GBR (LaJeunesse et al. 2003), highly specific for the corals in the genus Pavona from Hawaii (LaJeunesse et al. 2004), yet is a generalist among hosts from Zamami Island reefs. This example demonstrates the capacity for a symbiont to be specialized for 1 particular host in 1 region, but to display more generalized associations or greater prevalence at other locations. The extent to which host-symbiont specificity is expressed in geographically 
separate populations is predicted by the geographic mosaic theory of coevolution (Thompson 1994).

Differences in symbiont communities between central and southern regions indicate that the GBR is biogeographically partitioned. The similar symbiont compositions found at Rib, Feather and Curaçao reefs are probably possessed by other reefs from the central GBR region. Except for the more common types (e.g. C1, C3, C21, C15), few others were identified in the southern GBR survey (LaJeunesse et al. 2003). On the northern GBR, Types C1, C40, C3h and C8 were identified in corals from Lizard Island (Baker 1999, A. Baker \& T. LaJeunesse unpubl.). While these results indicate some similarity in symbiont assemblages between northern and central regions, other Symbiodinium spp. not identified from central or southern regions were also among those identified from Lizard Island (A. Baker \& T. LaJeunesse unpubl.). Based on the presence and/or absence of characteristic hostspecific symbionts, the GBR may be divided into a number of biogeographic provinces. Ayre \& Hughes (2000) reported a lack of geographic partitioning, as coral allozyme variation revealed moderate to high levels of gene flow along the entire GBR. Tracking the presence/absence of host-specific symbiont types, not influenced by environment across spatial scales encompassed by the GBR is potentially a rapid method for determining genetic connectivity between and within major reef systems, information important to conservation-related decisions.

Acknowledgements. The authors would like to thank the crew of the 'Lady Basten' for their hard work and support. S. Kininmonth produced the maps in Fig. 5 and waited patiently on the surface. A. Irikawa helped with coral identification from Okinawa. M. Wakeford assisted with diving and helped with host identification on the GBR. D. Fautin advised on anemone identifications and life-history traits. M. van Oppen and R. Berkelmans hosted our stay in Townsville. R. Berkelmans got us through the 'Australian' paper work. This research was made possible from funding provided by the Australian Research Council (O.H.-G.: ARCL245G), IOCUNESCO-World Bank Targeted Working Group on Coral Bleaching and Related Ecological Factors, Australian Institute of Marine Sciences, and the NSF (grant OCE-0137007 to W.K.F. and G.W.S.)

\section{LITERATURE CITED}

Avise JC (2000) Phylogeography: the history and formation of species. Harvard University Press, Cambridge, MA

Ayre DJ, Hughes TP (2000) Genotypic diversity and gene flow in brooding and spawning corals along the Great Barrier Reef, Australia. Evolution 54:1590-1605

Baillie BK, Belda-Baillie CA, Maruyama T (2000) Conspecificity and Indo-Pacific distribution of Symbiodinium genotypes (Dinophyceae) from giant clams. J Phycol 36: 1153-1161
Baker AC (1999) The symbiosis ecology of reef-building corals. PhD thesis, University of Miami, Miami

Baker AC (2001) Corals bleach to survive change. Nature 411: 765-766

Baker AC (2003) Flexibility and specificity in coral-algal symbiosis: diversity, ecology and biogeography of Symbiodinium. Annu Rev Ecol Evol Syst 34:661-689

Baker AC, Rowan R (1997) Diversity of symbiotic dinoflagellates (zooxanthellae) in scleractinian corals of the Caribbean and eastern Pacific. Proc 8th Int Coral Reef Symp 2:1301-1306

Benayahu Y (1997) Developmental episodes in reef soft corals: ecological and cellular determinants. Proc 8th Int Coral Reef Sym 2:1213-1218

Berkelmans R, Oliver JK (1999) Large-scale bleaching of corals on the Great Barrier Reef. Coral Reefs 18:55-60

Budd A (2000) Diversity and extinction in the Cenozoic history of Caribbean reefs. Coral Reefs 19:25-35

Buddemeier RW, Fautin DG (1993) Coral bleaching as an adaptive mechanism. BioScience 43:320-326

Burnett WJ (2002) Longitudinal variation in algal symbionts (zooxanthellae) from the Indian Ocean zoanthid Palythoa caesia. Mar Ecol Prog Ser 234:105-109

Chang SS, Prézelin BB, Trench RK (1983) Mechanisms of photoadaptation in three strains of the symbiotic dinoflagellate Symbiodinium microadriaticum. Mar Biol 76: 219-29

Chen CA, Lam KK, Nakano Y, Tsai W (2003) A stable association of the stress-tolerant zooxanthellae, Symbiodinium clade D, with the low-temperature tolerant coral, Oulastrea crispata (Scleractinia: Faviidae) in subtropical nonreefal coral communites. Zool Stud 42:540-550

Coffroth MA, Santos SR, Goulet TL (2001) Early ontogenetic expression of specificity in a cnidarian-algal symbiosis. Mar Ecol Prog Ser 222:85-96

Colley NJ, Trench RK (1983) Selectivity in phagocytosis and persistence of symbiotic algae by the scyphistoma stage of the jellyfish Cassiopeia xamachana. Proc R Soc Lond B 219:61-82

Collins LS, Budd A, Coates AG (1996) Earliest evolution associated with closure of the Tropical American Seaway. Proc Natl Acad Sci USA 93:6069-6072

Douglas AE (1998) Host benefit and the evolution of specialization in symbiosis. Heredity 81:599-603

Fabricius K, Alderslade P (2001) Soft corals and sea fans: a comprehensive guide to the tropical shallow water genera of the central-west Pacific, the Indian Ocean and the Red Sea. Australian Institute of Marine Science, Townsville and New Litho, Surrey Hills, Melbourne

Futuyma DJ, Moreno G (1988) The evolution of ecological specialization. Annu Rev Ecol Syst 19:207-233

Glynn PW, Maté JL, Baker AC, Calderon MO (2001) Coral bleaching and mortality in Panama and Ecuador during the 1997-1998 El Niño-southern oscillation event: spatial/ temporal patterns and comparisons with the 1982-1983 event. Bull Mar Sci 69:79-109

Goulet TL, Coffroth MA (2003) Stability of an octocoral-algal symbiosis over time and space. Mar Ecol Prog Ser 250: $117-124$

Hoegh-Guldberg O (1999) Climate change, coral bleaching and the future of the world's coral reefs. Mar Freshw Res 50:839-866

Hoegh-Guldberg O, Jones R, Ward S, Loh W (2002) Ecologyis coral bleaching really adaptive? Nature 415:601-602

Huelsenbeck JP, Ronquist F (2001) MrBays: Bayesian inference of phylogenetic trees. Bioinformatics 17:754-755

Iglesias-Prieto R, Trench RK (1997) Photoadaptation, photo- 
acclimation and niche diversification in invertebratedinoflagellate symbioses. Proc 8th Int Coral Reef Symp 2:1319-1324

Iglesias-Prieto R, Matta JL, Robins WA, Trench RK (1992) Photosynthetic response to elevated temperature in the symbiotic dinoflagellate Symbiodinium microadriaticum in culture. Proc Nat Acad Sci USA 89:10302-10305

Iglesias-Prieto R, Beltrán VH, LaJeunesse TC, Reyes-Bonilla $H$, Thomé PE (2004) Different algal symbionts explain the vertical distribution of dominant reef corals in the eastern Pacific. Proc R Soc Lond B 271:1757-1763

Jackson JBC (1994) Constancy and change of life in the sea. Phil Trans R Soc Lond B 344:55-60

Jones R, Hoegh-Guldberg O, Larkum AWD, Schreiber U (1998) Temperature induced bleaching of corals begins with impairment of dark metabolism in zooxanthellae. Plant Cell Environ 21:1219-1230

Kleypas JA, Buddemeier RW, Archer D, Gattuso JP, Langdon C, Opdyke BN (1999) Geochemical consequences of increased atmospheric carbon dioxide on coral reefs. Science 284:118-120

LaJeunesse TC (2001) Investigating the biodiversity, ecology, and phylogeny of endosymbiotic dinoflagellates in the genus Symbiodinium using the internal transcribed spacer region: in search of a 'species' level marker. J Phycol 37: 866-880

LaJeunesse TC (2002) Diversity and community structure of symbiotic dinoflagellates from Caribbean coral reefs. Mar Biol 141:387-400

LaJeunesse TC, Trench RK (2000) The biogeography of two species of Symbiodinium (Freudenthal) inhabiting the intertidal anemone, Anthopleura elegantissima (Brandt). Biol Bull (Woods Hole) 199:126-134

LaJeunesse TC, Loh WKW, van Woesik R, Hoegh-Guldberg O, Schmidt GW, Fitt WK (2003) Low symbiont diversity in southern Great Barrier Reef corals relative to those of the Caribbean. Limnol Oceanogr 48:2046-2054

LaJeunesse TC, Thornhill DJ, Cox EF, Stanton FG, Fitt WK, Schmidt GW (2004) High diversity and host-specificity observed among symbiotic dinoflagellates in reef coral communities from Hawaii. Coral Reefs 23:596-603

LaJeunesse TC, Lee S, Bush S, Bruno JF (2005) Persistence of non-Caribbean algal symbionts in Indo-Pacific mushroom corals released to Jamaica 35 years ago. Coral Reefs (in press)

Law R (1985) Evolution in a mutualistic environment. In: Boucher DH (ed) The biology of mutualism: ecology and evolution. Oxford University Press, New York, p 145-170

Little AF, Van Oppen JH, Willis BL (2004) Flexibility in algal endosymbioses shapes growth in reef corals. Science 304: 1492-1494

Loh WK, Carter D, Hoegh-Guldberg O (1998) Diversity of zooxanthellae from scleractinian corals of One Tree Island (The Great Barrier Reef). In: Greenwood JG, Hall NJ (eds) Proceedings of the Australian Coral Reef Society 75th Anniversary Conference, Heron Island. School of Marine Sciences, University of Queensland, Brisbane, p 141-150

Loh WK, Loi T, Carter D, Hoegh-Guldberg O (2001) Genetic variability of the symbiotic dinoflagellates from the wide ranging coral species Seriatopora hystrix and Acropora longicyathus in the Indo-West Pacific. Mar Ecol Prog Ser 222:97-107

Marshall PA, Baird AH (2000) Bleaching of corals on the Great Barrier Reef: differential susceptibilities among taxa. Coral Reefs 19:155-163

Pochon X, Pawlowski J, Zaninetti L, Rowan R (2001) High genetic diversity and relative specificity among Symbio- dinium-like endosymbiotic dinoflagellates in soritid foraminiferans. Mar Biol 139:1069-1078

Pochon X, LaJeunesse TC, Pawlowski J (2004) Biogeographic partitioning and host specialization among foraminiferan dinoflagellate symbionts (Symbiodinium, Dinophyta). Mar Biol 146:17-27

Richmond RH, Hunter CL (1990) Reproduction and recruitment of corals: comparisons among the Caribbean, the tropical Pacific and the Red Sea. Mar Ecol Prog Ser 60:185-203

Rodriquez-Lanetty M, Loh W, Carter D, Hoegh-Guldberg O (2001) Latitudinal variability in symbiont specificity within the widespread scleractinian coral Plesiastrea versipora. Mar Biol 138:1175-1181

Rowan R (1998) Diversity and ecology of zooxanthellae on coral reefs. J Phycol 34:407-417

Rowan R, Powers DA (1991) A molecular genetic classification of zooxanthellae and the evolution of animal-algal symbiosis. Science 251:1348-1351

Rowan R, Knowlton N, Baker A, Jara J (1997) Landscape ecology of algal symbionts creates variation in episodes of coral bleaching. Nature 388:265-269

Ryland JS (1997) Reproduction in zoanthidea (Anthozoa: Hexacorallia). Invertebr Reprod Dev 31:177-188

Santos SR, Gutierrez-Rodriquez C, Lasker HR, Coffroth MA (2003) Symbiodinium sp. associations in the gorgonian Pseudopterogorgia elisabethae in the Bahamas: high levels of genetic variability and population structure in symbiotic dinoflagellates. Mar Biol 143:111-120

Santos SR, Shearer TL, Hannes AR, Coffroth MA (2004) Finescale diversity and specificity in the most prevalent lineage of symbiotic dinoflagellates (Symbiodinium, Dinophyceae) of the Caribbean. Mol Ecol 13:459-469

Seutin G, White BN, Boag PT (1991) Preservation of avian blood and tissue samples for DNA analyses. Can J Zool 69:82-92

Skirving W, Guinotte J (2001) The sea surface temperature story on the Great Barrier Reef during the coral bleaching event of 1998. In: Wolanski E (ed) Oceanographic processes of coral reefs. Physical and biological links in the Great Barrier Reef. CRC Press, Boca Raton, p 301-313

Swofford DL (1999) PAUP*, phylogenetic analysis using parsimony ( ${ }^{*}$ and other methods), Version $4.0 \mathrm{~b} 10$. Sinauer, Sunderland, MA

Thompson JN (1994) The coevolutionary process. University Chicago Press, Chicago, IL

Toller WW, Rowan R, Knowlton N (2001) Zooxanthellae of the Montastraea annularis species complex: patterns of distribution of four taxa of Symbiodinium on different reefs and across depths. Biol Bull (Woods Hole) 201:348-359

Trench RK (1997) Diversity of symbiotic dinoflagellates and the evolution of microalgal-invertebrate symbioses. Proc 8th Int Coral Reef Symp 2:1275-1286

Van Oppen MJH (2004) Mode of zooxanthella transmission does not affect zooxanthella diversity in acroporid corals. Mar Biol 144:1-7

Van Oppen MJH, Palstra FP, Piquet AMT, Miller DJ (2001) Patterns of coral-dinoflagellate associations in Acropora: significance of local availability and physiology of Symbiodinium strains and host-symbiont selectivity. Proc R Soc Lond B 268:1759-1767

Veron JEN (1995) Corals in space and time. University of New South Wales Press, Sydney

Veron JEN (2000) Corals of the world, Vol 1-3. Australian Institute of Marine Science, Townsville

Warner EM, Fitt WK, Schmidt GW (1999) Damage to photosystem II in symbiotic dinoflagellates: a determinant of coral bleaching. Proc Natl Acad Sci USA 96:8007-8012 